\title{
Complementary and Alternative Medicine Use in a Pregnant Population, Northwest Ethiopia
}

\author{
Yohannes Kelifa Emiru $\mathbb{D}^{1},{ }^{1}$ Betelhem Anteneh Adamu $\mathbb{D}^{1},{ }^{1}$ Melak Erara, ${ }^{2}$ Tigist Chanie, ${ }^{3}$ \\ and Abyot Endale Gurmu ${ }^{1}$ \\ ${ }^{1}$ Department of Pharmacognosy, School of Pharmacy, College of Medicine and Health Sciences, University of Gondar, \\ Gondar, Ethiopia \\ ${ }^{2}$ Department of Clinical Pharmacy, School of Pharmacy, College of Medicine and Health Sciences, University of Gondar, \\ Gondar, Ethiopia \\ ${ }^{3}$ University of Gondar Compressive Specialized Hospital, University of Gondar, Gondar, Ethiopia
}

Correspondence should be addressed to Yohannes Kelifa Emiru; johnkelifa@gmail.com and Betelhem Anteneh Adamu; betelhemadamu73@gmail.com

Received 4 August 2020; Revised 6 July 2021; Accepted 29 July 2021; Published 9 August 2021

Academic Editor: Robert Gaspar

Copyright (C) 2021 Yohannes Kelifa Emiru et al. This is an open access article distributed under the Creative Commons Attribution License, which permits unrestricted use, distribution, and reproduction in any medium, provided the original work is properly cited.

\begin{abstract}
Background. Complementary and alternative medicine (CAM) appears to be the source of healthcare particularly in the majority of pregnant communities of Africa due to its intrinsic qualities as well as its accessibility and affordability. Despite acknowledged benefits of CAM use in pregnancy, majority of users are unaware of its safety and effects on fetal development. The present study was aimed at examining CAM use among pregnant women in Northwest Ethiopia to provide an opportunity for future investigations on the effectiveness of CAM modalities in the management of pregnancy-related complications across the country. Methods. This was an institution-based cross-sectional study which was conducted at Poly Clinic Health Center in the Northwest part of Ethiopia between March and May 2018. Two hundred and eighty two Ethiopian women were conveniently recruited to take part in the study. Structured questioners were used for the survey. Descriptive statistics of sociodemographic and CAM use characteristics were expressed in frequencies and proportions. Chi-square test was performed to determine the difference between CAM user and nonuser. Besides, binary logistic regression analyses were performed to examine predictors of CAM use in the study population. The result was considered statistically significant if $P$ value $\leq 0.05$. Results. The prevalence rate of CAM use in pregnant women was $89.36 \%$ with the commonest practice of spiritual healing (65.2\%) and herbal supplement (51.8\%) CAM therapies. Use of CAM positively associated with marital status and previous number of children. The odds of using CAM among single/not married women were 3.22 times higher (COR: 3.22, CI: 1.07-9.64) as compared to married women. Pregnant women with no children were 3.30 times more likely (COR: 3.30, CI: 0.92-11.84) to use CAM than those women having $\geq 3$ children. Lower odds of using CAM significantly associated with educational level (COR: 0.20, CI: 0.046-0.93) and antenatal care (COR: 0.45, CI: 0.18-1.13) in a binary logistic regression model. Conclusions. A considerable number of pregnant women were utilizing CAM including herbal products as part of their maternity care. This finding provides a reference on the use of CAM for policy-makers, health professionals, and parents. Further studies are needed to investigate the effectiveness and safety of specific CAM modalities with particular focus on herbal medicinal products.
\end{abstract}

\section{Introduction}

In resource-constrained health settings, complementary and alternative medicines (CAM) are commonly used because they are often more widely available and more affordable than conventional therapies. The term CAM refers to a wide set of healthcare practices that are not integrated into the current healthcare system and are not part of that country's tradition [1]. It comprises some form of caring approach including acupuncture, especial diets, massage therapy, 
medicinal plants, biologic feedback, and relaxation techniques $[1,2]$. Women have become more informed about their health and use print media, television, radio, and internet to get information on which to base their health decisions. As a result, pregnant women are increasingly recognized CAM and they are leading the utilization trends of CAM for their healthcare and well-being [2,3]. In the United States of America [4, 5] and Australia [6], for instance, they reported a practice rate of $87 \%$ and $91 \%$ CAM use during pregnancy, respectively.

Studies revealed the use of CAM throughout the pregnancy period for the treatment of nausea and vomiting, as well as for illnesses due to pregnancy such as fatigue, respiratory, and skin issues and nutritional benefits $[7,8]$. Despite known benefits of CAM use in pregnancy, majority of users are unaware of its safety and effects on fetal development and possibility of CAM-drug interaction $[1,7,9]$. Together with this, a substantial proportion of women often fail to disclose their gestational use of CAM to their maternity providers $[6,7]$. In Ethiopia, CAM is culturally acceptable and widely utilized, predominantly for the belief that CAM is natural, thus safer than conventional medicine. A previous a study done in Northwest Ethiopia has shown that higher than $48 \%$ pregnant women use herbal medicine like ginger (Zingiber officinale) and demakese (Ocimum lamiifolium) [8]. However, there is paucity of evidence on the prevalence and predictors of other types of CAM modalities such as spiritual healing, biological-based therapies, and manipulative and body-based therapy practices among pregnant women in the nation. Hence, this study was aimed at investigating the prevalence, types, and sociodemographic factors associated with CAM usage among pregnant women in Northwest Ethiopia. The findings of this study will provide supporting evidence that could guide decision making at the system, institutional, and individual level concerning CAM use in pregnancy and provide an opportunity for future investigations on the effectiveness of these modalities in the management of pregnancy-related complications across the country.

\section{Methods and Materials}

2.1. Study Design and Setting. This was an institution-based cross-sectional study which was carried out at Poly Clinic Health Center (PCHC) from March to May 2018. The source population was pregnant women who attended antenatal care clinics. The study area is found in Gondar Town, North Gondar, which is located $738 \mathrm{~km}$ far away from Addis Ababa, capital of Ethiopia. The town is found at 2700 meters above sea level and has a total population of 333,103 . PCHC is one of the governmental health centers serving for 101,317 populations.

2.2. Sample Size and Sampling Procedure. A convenience sampling technique was used in this study. Eligible participants had to meet a set of inclusion criteria recruited in the study. These criteria are Ethiopian nationality only (as this study was intended to explore CAM use particularly in Ethiopian population); age $\geq 18$ years, willing to participate, and who had provided verbal consent to participate in the study; and completely filled the questionnaire form and answered all questions. Pregnant women who had severe physical and mental illness were excluded.

2.3. Data Collection Tool. The survey questionnaire used in the study was adapted and developed following a detailed review of previous relevant works $[1,8,10]$ with some modifications. The questionnaire was constructed in their native language (Amharic) and translated back into English to check its consistency. The content of the questionnaire was piloted among 15 pregnant women visiting Maraki Health Center (one of the public health centers found in Gondar Town) to gather information on its understandability, time consumed by each question, consistency among related variables, and acceptability. Following the results of the pre-test, necessary correctionsand amendments were made on the questionnairebefore the actual data collection was initiated The respondents were interviewed using a structured questionnaire which consists of 4 parts: part I: eleven questions related to sociodemographic characteristic of the respondents; part II: six practice-related questions for CAM users; part III: eleven questions asking the perceived reasons for CAM use; and part IV: four queries demanding types of CAM therapies frequently practiced in the course of pregnancy.

2.4. Ethical Approval. Ethical clearance was obtained from the ethics review committee of School of Pharmacy, College of Medicine and Health Science, University of Gondar. Additionally, the permission to undertake the study was received from the PCHC director. The study subjects were informed about the objective and importance of the study, and oral consent was obtained from each participant. All respondents were assured of the confidentiality regarding the responses obtained from them.

2.5. Statistical Analysis. Statistical analysis was performed using Statistical Package for the Social Sciences (SPSS) version 22.0 for Windows. Descriptive statistics of sociodemographic and CAM use characteristics were expressed in frequencies and proportions. The main outcome variable in the analysis was CAM use. In order to determine the differences in characteristics between pregnant women who have used CAM and those who did not, chi-square test was performed. Moreover, the univariate and multivariate logistic regression analyses were performed to examine predictors of CAM use in the study population. For a variable to be included in the multiple regression model, it had to be significantly associated with the main outcome in the univariate analysis. Odds ratios and their respective 95\% confidence intervals were calculated. Statistical significance was set at a $P$ value $\leq 0.05$.

\section{Results}

3.1. Characteristics of CAM and Non-CAM User Pregnant Women. Among the 282 pregnant subjects who had attended the antenatal care, $252(89.36 \%)$ pregnant women reported to be using some form of CAM modalities (Table 1). The vast majority (90.8\%) were married, and only $11 \%$ had attended 
TABLE 1: Sociodemographic characteristics of pregnant women and their association with CAM use in univariate and multiple logistic regression models $(N=282)$.

\begin{tabular}{|c|c|c|c|c|c|c|c|}
\hline \multirow{2}{*}{ Characteristics } & \multirow{2}{*}{ Overall $N(\%)$} & \multicolumn{2}{|c|}{ CAM use $N(\%)$} & \multirow{2}{*}{$P$ value $^{a}$} & \multirow{2}{*}{ COR $(95 \% \mathrm{CI})^{*}$} & \multirow{2}{*}{$P$ value $^{a}$} & \multirow{2}{*}{ AOR $(95 \% \mathrm{CI})^{*}$} \\
\hline & & Yes & No & & & & \\
\hline \multicolumn{8}{|l|}{ Age (year) } \\
\hline$<20$ & $17(6)$ & $15(6.0)$ & $2(6.7)$ & & 1 (ref) & & \\
\hline $20-30$ & $176(62.4)$ & $156(61.9)$ & $20(66.7)$ & 0.96 & $0.96(0.20-4.52)$ & - & - \\
\hline$>30$ & $89(31.6)$ & $81(32.1)$ & $8(26.7)$ & 0.71 & $0.74(0.14-3.83)$ & - & - \\
\hline \multicolumn{8}{|l|}{ Religion } \\
\hline Orthodox & $222(78.7)$ & $200(79.4)$ & $22(73.3)$ & 0.123 & $0.11(0.007-1.82)$ & - & - \\
\hline Muslim & $55(19.5)$ & $48(19.0)$ & $7(23.3)$ & 0.99 & - & - & - \\
\hline Protestant & $3(1.1)$ & $3(1.2)$ & $0(0.0)$ & 0.19 & $0.15(0.008-2.60)$ & - & - \\
\hline Catholic & $2(0.7)$ & $1(0.4)$ & $1(3.3)$ & & 1 (ref) & & \\
\hline \multicolumn{8}{|l|}{ Marital status } \\
\hline Married & $256(90.8)$ & $232(92.1)$ & $24(80.0)$ & & 1 (ref) & & 1 (ref) \\
\hline Single & $20(7.1)$ & $15(6.0)$ & $5(16.7)$ & 0.036 & $3.22(1.07-9.64)$ & 0.18 & $2.39(0.663-8.65)$ \\
\hline Divorced & $4(1.4)$ & $3(1.2)$ & $1(3.3)$ & 0.31 & $3.22(0.32-32.19)$ & 0.32 & $3.50(0.28-43.20)$ \\
\hline Widowed & $2(0.7)$ & $2(0.8)$ & $0(0.0)$ & 0.99 & - & 0.99 & - \\
\hline \multicolumn{8}{|l|}{ Educational } \\
\hline Unable to write and read & $78(27.7)$ & $75(29.8)$ & $3(10.0)$ & 0.04 & $0.20(0.046-0.93)$ & 0.14 & $0.29(0.05-1.53)$ \\
\hline Able to write and read & $44(15.6)$ & $38(15.1)$ & $6(20.0)$ & 0.76 & $0.82(0.22-2.97)$ & 0.95 & $1.03(0.26-4.10)$ \\
\hline Primary school & $53(18.8)$ & $50(19.8)$ & $3(10.0)$ & 0.13 & $0.31(0.069-1.40)$ & 0.30 & $0.44(0.09-2.11)$ \\
\hline Secondary school & $76(27)$ & $63(25.0)$ & $13(43.3)$ & 0.90 & $1.07(0.34-3.31)$ & 0.96 & $1.02(0.31-3.31)$ \\
\hline College/university & $31(11)$ & $26(10.3)$ & $5(16.7)$ & & 1 (ref) & & 1 (ref) \\
\hline \multicolumn{8}{|l|}{ Occupation } \\
\hline Unemployed/house wife & $162(57.4)$ & $147(58.3)$ & $15(50.0)$ & 0.37 & $0.54(0.14-2.08)$ & - & - \\
\hline Part time & $43(15.2)$ & $40(15.9)$ & $3(10.0)$ & 0.29 & $0.40(0.07-2.19)$ & - & - \\
\hline Full time & $58(20.6)$ & $49(19.4)$ & $9(30.0)$ & 0.97 & $0.98(0.23-4.06)$ & - & - \\
\hline Student & $19(6.7)$ & $16(6.3)$ & $3(10.0)$ & & 1 (ref) & & \\
\hline \multicolumn{8}{|c|}{ Monthly income (Ethiopian birr) } \\
\hline No income & $20(7.1)$ & $20(7.9)$ & $0(0.0)$ & 0.99 & - & - & - \\
\hline$<500$ & $86(30.5)$ & $82(32.5)$ & $4(13.3)$ & 0.19 & $0.25(008-0.79)$ & - & - \\
\hline $500-999$ & $83(29.4)$ & $72(28.6)$ & $11(36.7)$ & 0.59 & $0.79(0.34-1.84)$ & - & - \\
\hline$>1000$ & $93(33)$ & $78(31.0)$ & $15(50.0)$ & & 1 (ref) & & \\
\hline \multicolumn{8}{|l|}{ Previous number of children } \\
\hline No & $108(38.3)$ & $92(36.5)$ & $16(53.3)$ & 0.05 & $3.30(0.92-11.84)$ & 0.42 & $1.82(0.41-8.05)$ \\
\hline 1 & $60(21.3)$ & $52(20.6)$ & $8(26.7)$ & 0.12 & $2.92(0.73-11.60)$ & 0.31 & $2.16(0.48-9.71)$ \\
\hline 2 & $54(19.1)$ & $51(20.2)$ & $3(10.0)$ & 0.89 & $1.11(0.21-5.78)$ & 0.73 & $0.73(0.12-4.31)$ \\
\hline$\geq 3$ & $60(21.3)$ & $57(22.6)$ & $3(10.0)$ & & 1 (ref) & & 1 (ref) \\
\hline \multicolumn{8}{|l|}{ Pregnancy status } \\
\hline $1^{\text {st }}$ trimester & $55(19.5)$ & $47(18.7)$ & $8(26.7)$ & & 1 (ref) & & \\
\hline $2^{\text {nd }}$ trimester & $124(44)$ & $109(43.3)$ & $15(50.0)$ & 0.65 & $0.80(0.32-2.03)$ & - & - \\
\hline $3^{\text {rd }}$ trimester & $103(26.5)$ & $96(38.1)$ & $7(23.3)$ & 0.12 & $0.42(0.14-1.25)$ & - & - \\
\hline \multicolumn{8}{|l|}{ Antenatal care } \\
\hline No & $47(16.7)$ & $39(15.5)$ & $8(26.7)$ & & 1 (ref) & & 1 (ref) \\
\hline Midwife & $209(74.1)$ & $191(75.8)$ & $18(60.0)$ & 0.05 & $0.45(0.18-1.13)$ & 0.62 & $0.77(0.27-2.18)$ \\
\hline Nurse & $10(3.5)$ & $8(3.2)$ & $2(6.7)$ & 0.82 & $1.21(0.21-6.84)$ & 0.39 & $2.30(0.34-15.59)$ \\
\hline Physician & $16(5.7)$ & $14(5.6)$ & $2(6.7)$ & 0.67 & $0.69(0.13-3.68)$ & 0.93 & $1.08(0.18-6.50)$ \\
\hline
\end{tabular}


TABLE 1: Continued.

\begin{tabular}{|c|c|c|c|c|c|c|c|}
\hline \multirow{2}{*}{ Characteristics } & \multirow{2}{*}{ Overall $N(\%)$} & \multicolumn{2}{|c|}{ CAM use $N(\%)$} & \multirow{2}{*}{$P$ value ${ }^{a}$} & \multirow{2}{*}{$\operatorname{COR}(95 \% \mathrm{CI})^{*}$} & \multirow{2}{*}{$P$ value ${ }^{a}$} & \multirow{2}{*}{$\operatorname{AOR}(95 \% \mathrm{CI})^{*}$} \\
\hline & & Yes & No & & & & \\
\hline \multicolumn{8}{|l|}{ Residency } \\
\hline Urban & $241(85.5)$ & $214(84.9)$ & $27(90.0)$ & 0.45 & $0.62(0.18-2.16)$ & - & - \\
\hline Rural & $41(14.5)$ & $38(15.1)$ & $3(10.0)$ & & 1 (ref) & & \\
\hline
\end{tabular}

CAM: complementary and alternative medicine; ${ }^{a} \mathrm{P}$ value refers to the significance of the differences between CAM users and non-CAM users using the chisquare test; COR: crude odds ratio; AOR: adjusted odds ratio; CI: confidence interval; * odds ratio and their 95\% CI were derived using a binary logistic regression model with CAM use as the dependent variable.

TABLE 2: The observed responses for the use of CAM in the study participants $(N=252)$.

\begin{tabular}{|c|c|}
\hline Queries & $\begin{array}{l}\text { Overall } n \\
(\%)\end{array}$ \\
\hline \multicolumn{2}{|l|}{ Responses to quality of life assessment ${ }^{\mathrm{a}}$} \\
\hline Is CAM therapy improving your QOL? & $86(30.5)$ \\
\hline My overall health is better & $162(57.4)$ \\
\hline I am not depressed all the time & $126(44.7)$ \\
\hline I have less fatigue & $176(62.4)$ \\
\hline I have more energy & $78(27.7)$ \\
\hline I can sleep well & $185(65.6)$ \\
\hline I have better memory & $162(57.4)$ \\
\hline $\begin{array}{l}\text { I do not have frequent nausea/vomiting or other } \\
\text { health problem }\end{array}$ & $83(29.4)$ \\
\hline I am not sick all the time & $75(26.6)$ \\
\hline \multicolumn{2}{|l|}{ Disclosure of CAM use to HCPs } \\
\hline Yes & $95(33.7)$ \\
\hline No & $157(55.7)$ \\
\hline \multicolumn{2}{|l|}{ Reasons for not reporting to $H C P s^{\mathrm{a}}$} \\
\hline Does not need the HCP's approval & $7(2.5)$ \\
\hline $\begin{array}{l}\text { The HCPs would be unsupportive and would } \\
\text { discourage }\end{array}$ & $52(18.4)$ \\
\hline Insufficient information of CAM & $19(6.7)$ \\
\hline The HCPs do not ask about CAM & $57(20.2)$ \\
\hline \multicolumn{2}{|l|}{ Source of information on CAM use } \\
\hline Family/friend/relative & $140(49.6)$ \\
\hline Media (internet/television/radio/book) & $16(5.7)$ \\
\hline Health practitioner & $40(14.2)$ \\
\hline Pregnant women who used herbal medicines & $12(4.3)$ \\
\hline CAM practitioners & $18(6.4)$ \\
\hline \multicolumn{2}{|l|}{ Awareness of drug-herb interaction } \\
\hline Yes & $94(33.3)$ \\
\hline No/I do not know & $158(56)$ \\
\hline \multicolumn{2}{|l|}{ Satisfaction level with CAM use } \\
\hline Satisfied & $59(20.9)$ \\
\hline Average & $125(44.3)$ \\
\hline Dissatisfied & $68(24.1)$ \\
\hline
\end{tabular}

CAM: complementary and alternative medicine; QOL: quality of life; HCPs: healthcare providers; ${ }^{a}$ the values do not sum up to $100 \%$ since multiplechoice answers could have been selected. college/university, whereas $27 \%$ had secondary education and $27.7 \%$ were unable to write and read. Most of the participants were unemployed (57.4\%), and only 33\% were earning more than Ethiopian birr (ETB) 1000 per month $(\approx$ United States Dollar (USD) 32), while $30.5 \%$ and $29.4 \%$ had a monthly income of ETB $<500$ and 500-99, respectively. In respect of pregnancy status, $44 \%$ of women were found in $2^{\text {nd }}$ trimester and majority $(74.1 \%)$ had visited midwifery for the antenatal care.

In a univariate logistic regression model, those who were single had higher odds of using CAM (COR: 3.22, CI: 1.079.64) compared to married or divorced or widowed women. Similarly, no children in previous time showed higher odds of CAM use (COR: 3.30, CI: 0.92-11.84). Pregnant women who were unable to write and read (COR: 0.20, CI: 0.0460.93 ) and had visited midwifery for antenatal care (COR: 0.45, CI: 0.18-1.13) reported lower odds of using CAM. However, none of these variables was significantly associated with CAM use in multiple logistic regression analysis as shown in Table 1.

3.2. The Perceived Responses for Questions Linked to CAM Uses and Characterization of Types of CAM Used across Pregnancy Periods. The response in relation to CAM use among study subjects is presented in Table 2. Most of the CAM users were reported having slept well (65.6\%) and less fatigue $(62.4 \%)$ in response to CAM use-related quality of life (QOL) while a small proportion of participants responded having more energy (27.7\%) and not sick all the time (26.6\%) as CAM use-associated QOL. In the case of level of satisfaction in CAM use, $44.3 \%$ respondents had shown an average level of satisfaction for CAM therapies but about $56 \%$ of CAM users were not aware of any potential herbaldrug interaction. Majority of the pregnant women (55.7\%) informed that they did not disclose CAM use to their HCPs. The reasons for not disclosing CAM use were reported to be 'HCPs do not ask' (20.2\%), and 'HCPs may be unsupportive and discourage' (18.4\%). Less reported reasons were insufficient information of CAM (6.7\%) and CAM use does not need approval of HCPs $(2.5 \%)$.

Regarding source of information for CAM use, nearly half of the participants relied 'family/friend/relative' (49.6\%) while $14.2 \%$ answered 'health practitioner'. The utmost strongly agreed reasons for CAM use were accessibility and availability of CAM (28\%), family/culture/religious beliefs (22\%), more natural (17.4\%), and the beneficial effect on quality of life and health of their fetus (15.2\%) as described in Table 3. 
TABLE 3: Reasons for using $\mathrm{CAM}^{\dagger}$ in pregnancy $(N=252)$.

\begin{tabular}{|c|c|c|c|}
\hline \multirow{2}{*}{ Reasons for using CAM } & \multicolumn{3}{|c|}{ Responses $N(\%)$} \\
\hline & Strongly agree & Agree & Disagree \\
\hline Beneficial effect on quality of life and health ${ }^{\mathrm{a}}$ & $43(15.2)$ & $99(35.1)$ & $110(39.0)$ \\
\hline Its more natural & $49(17.4)$ & $151(53.5)$ & $52(18.4)$ \\
\hline CAM is accessible and available & $79(28.0)$ & $121(42.9)$ & $52(18.4)$ \\
\hline Improves nutritional status & $12(4.3)$ & $64(22.7)$ & $176(62.4)$ \\
\hline Less risk for fetus than convectional drugs & $20(7.1)$ & $63(22.3)$ & $169(59.9)$ \\
\hline Lack of trust on conventional treatments & $9(3.2)$ & $52(18.4)$ & $191(67.7)$ \\
\hline Dissatisfaction with conventional therapy & $6(2.1)$ & $62(22.0)$ & $184(65.2)$ \\
\hline Family/culture/religious beliefs & $62(22.0)$ & $127(45.0)$ & $63(22.3)$ \\
\hline Previous experience of CAM use & $21(7.4)$ & $120(42.6)$ & $111(39.4)$ \\
\hline Control over situation $^{\mathrm{b}}$ & $13(4.6)$ & $78(27.7)$ & $161(57.1)$ \\
\hline
\end{tabular}

CAM: complementary and alternative medicine; ${ }^{\dagger}$ the values do not sum up to $100 \%$ since data from CAM nonusers have not been selected; ${ }^{a}$ beneficial effect on quality of life and physical health of their fetus; ${ }^{\mathrm{b}} \mathrm{CAM}$ therapies gave a sense of control or autonomy over the situation.

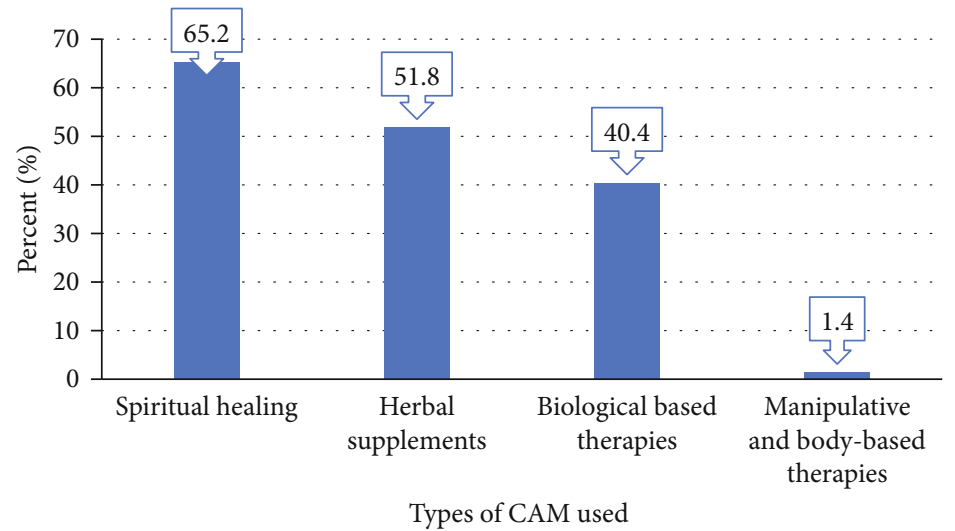

FIGURE 1: Frequency (\%) and types of CAM therapies used during pregnancy.

Spiritual healing (65.2\%) and herbal supplements $(51.8 \%)$ were found to be the commonest types of CAM therapies used throughout pregnancy in the present survey as it is portrayed in Figure 1. The most frequently consumed herbal supplements were ginger (Zingiber officinale) (43.6\%), garlic (Allium sativum) (38.3\%), and demakese (Ocimum lamiifolium) (36.2\%) (Figure 2).

\section{Discussion}

The present study was aimed at examining the prevalence and types of CAM therapies along with associated factors of CAM use during pregnancy. Despite a scarcity of evidence for efficacy and safety, CAM use is reportedly increasing across the globe [2, 3]. In this study, out of 252 women, $89.36 \%$ had reported CAM use at least once during pregnancy for strongly appreciated reasons like accessibility and availability of CAM treatments as well asculture/religionrelated beliefs. Similarly, a study in Australia reported CAM use as high as $87 \%$ [11]. In contrast, one study done in the United Kingdom evidenced lower (26.7\%) prevalence of CAM use in pregnancy. Moreover, three studies [12-14] from the USA reported lesser CAM use among pregnant women. The discrepancy in the prevalence of CAM use may be due to variation in sample size of participants surveyed, knowledge and experience of women, difference in advancement of health system across the countries, and scarcity in availability and access of medical services. In the current work, substantial increment of CAM use was observed in the first and second trimester in line with Mohamed et al.'s [15] study but a study undertaken in Qatar reported the relative decreases in the third trimester.

In this study, the commonest types of CAM modalities used during gestation were spiritual healing and herbal supplements followed by biological-based therapy. In accordance with previous studies conducted in the Northwest part of Ethiopia [8] and Alexandria [16], herbal supplements used by a higher proportion of pregnant women were Zingiber officinale, Allium sativum, and Ocimum lamiifolium. On the other hand, commonly used herbal supplements/preparations in Virginia, Australia, Norway, and Tuscany were reported to be peppermint, raspberry, fennel, and St. John's wort [17-20]. The inconsistency in the pattern of herbal supplement items between the studies might be due to availability, accessibility, affordability, distribution, and traditional claim/belief difference in the use of CAM for pregnancyrelated medical conditions. Evidence on efficacy and safety of herbs indicated for pregnant populations is inadequate. 


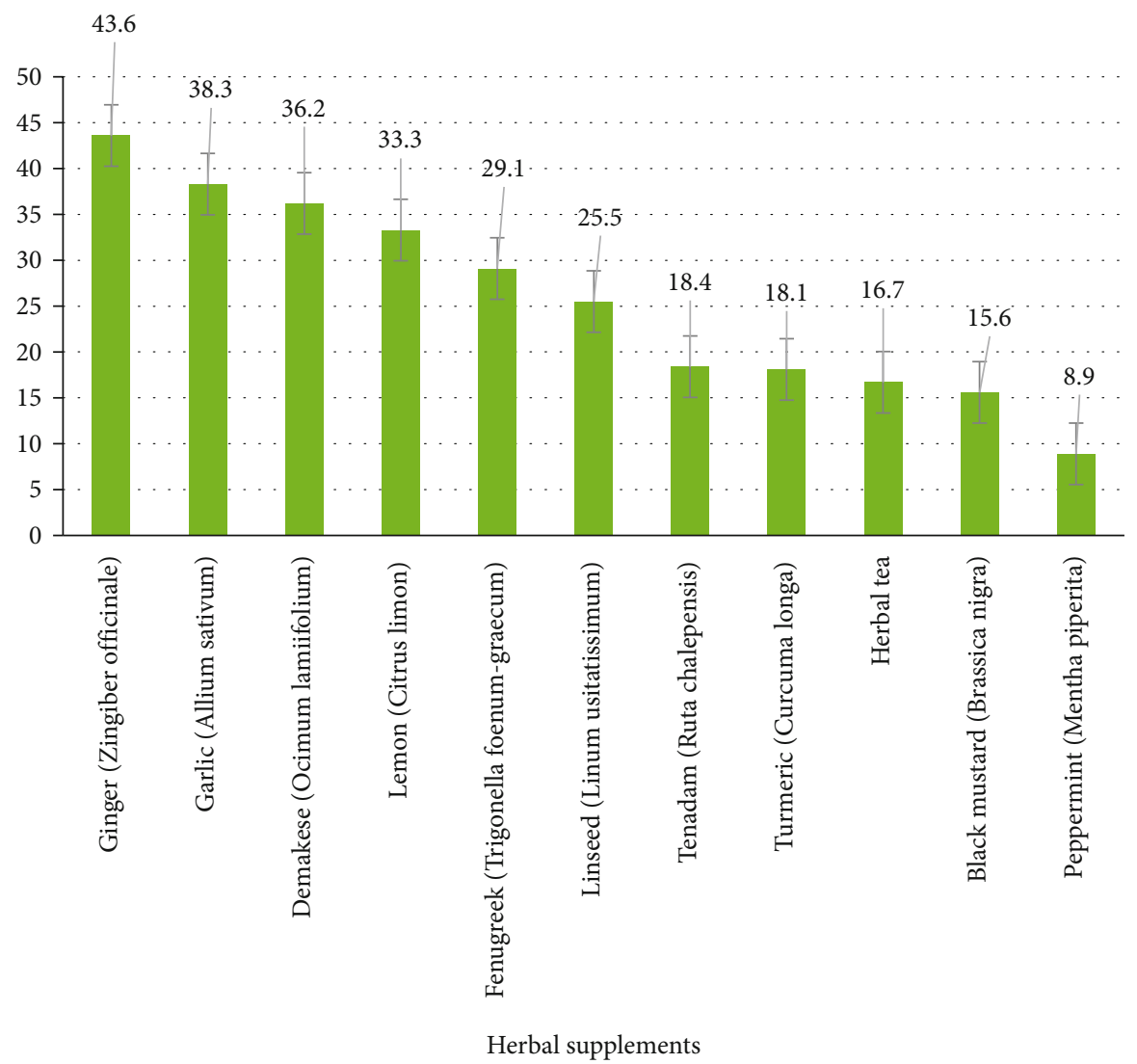

FiguRE 2: Frequency (\%) and list of herbal supplements used during pregnancy.

Chamomile and peppermint for morning sickness for instance were shown risky in $6 \%$ of studies [21,22]. Zingiber officinale and raspberry leaf were also evidenced as unsafe in $12 \%$ and $15 \%$ of the studies, respectively [21]. Fenugreek oil also needs to be consumed with caution during pregnancy due to its hypoglycemic effect and its stimulatory effect on oxytocin secretion resulting in uterine contraction [23]. The use of herbal products is not usually tested in clinical trials, and also, they are not included in the FDA pregnancy categories, giving a false impression of safety which could result in immense risk to the mother and fetus and elicit adverse effects including teratogenicity as well [24-26].

Concomitant use of herbs and conventional medications may result to undesired effects [27]. Remarkably, majority of pregnant women in the current study had possessed less awareness to herb-drug interaction while less proportion (33.7\%) of women were reported to disclose CAM use to their HCPs. These results agree with the findings of other studies, in which $37.2 \%$ of pregnant women informed their HCPs [28]. Although these findings differ from a published study [29], they have reported that $65.8 \%$ of pregnant women disclosed uses of some form of CAM therapies to their physicians. Other studies also revealed that the reporting level of pregnant women about CAM uses to their HCPs ranges from $24 \%$ to $52 \%$ [30, 31]. Most importantly, results of the present study indicated 'HCPs' unsupportiveness and discouragement' and 'omission of HCPs to ask' were the major reasons for nondisclosure of CAM use. Other reasons that were speculated in a previous work [32] included fear and unwillingness to discuss with HCPs.

In this study, family/friends/relatives were found to be the most common sources of information to use CAM in agreement with John and Shantakumari et al.'s findings [33]. However, the findings of the current study do not support the previous researches which showed the health practitioner as a source of information [34-36]. The current study confirmed the association of CAM use with marital status and number of children previously. The odds of using CAM among single/not married pregnant women were 3.22 times higher as compared to married women. Pregnant women with no children were 3.30 times more likely to use CAM than those women having $\geq 3$ children. Contrary to earlier findings $[8,37-40]$, this study indicated that lower odds of CAM use associated with educational level and antenatal care. Several limitations to this study need to be acknowledged while interpreting the results. First, the study did not identify a causal association related to CAM use and pregnancy. Secondly, a survey data is based on selfreport and therefore prone to recall bias.

\section{Conclusions}

Evidence from this study suggests that a significant proportion of pregnant women were utilizing CAM including herbal products as part of their maternity care. The most obvious finding to emerge from this study is that a 
considerable number of women failed to disclose the use of CAM modalities for HCPs. These findings provide a reference on the use of CAM in pregnancy for policy-makers, health professionals, and parents. Further studies are warranted to explore the effectiveness and safety of CAM therapies like herbal medicinal products and potential effects of long-term use as well as possible interactions of herbal medicinal products with concomitantly used conventional medicines.

\section{Data Availability}

The materials and data supporting the findings of this study are available from the corresponding author upon reasonable request.

\section{Conflicts of Interest}

The authors declare that there is no conflict of interests regarding the publication of this paper.

\section{Authors' Contributions}

YKE was involved in conception, study tool development, data analysis, final write-up, editing, and approval of the final manuscript. BAA was involved in conception and revising the final manuscript. ME and TC were involved in data collection and write-up of the first draft of the manuscript. AEG was involved in principal supervision and revising the final manuscript. All authors read and approved the final manuscript.

\section{Acknowledgments}

The authors would like to appreciate the support of School of Pharmacy, University of Gondar, and PCHC officer in facilitating the data collection process. The authors also would like to thank the study participants.

\section{References}

[1] T. Y. Teo, J. Yap, T. Shen, and K. K. Yeo, "Complementary and alternative medicine use amongst patients with cardiovascular disease in Singapore," BMC Complementary and Alternative Medicine, vol. 16, no. 1, p. 446, 2016.

[2] S. Warriner, K. Bryan, and A. M. Brown, "Women's attitude towards the use of complementary and alternative medicines (CAM) in pregnancy," Midwifery, vol. 30, no. 1, pp. 138-143, 2014.

[3] J. Adams, C. W. Lui, D. Sibbritt et al., "Women's use of complementary and alternative medicine during pregnancy: a critical review of the literature," Birth, vol. 36, no. 3, pp. 237-245, 2009.

[4] G. S. Birdee, K. J. Kemper, R. Rothman, and P. Gardiner, "Use of complementary and alternative medicine during pregnancy and the postpartum period: an analysis of the National Health Interview Survey," Journal of Women's Health, vol. 23, no. 10, pp. 824-829, 2014.

[5] J. L. Bishopa, K. Northstone, J. R. Green, and E. A. Thompson, "The use of complementary and alternative medicine in pregnancy: data from the Avon Longitudinal Study of Parents and
Children (ALSPAC)," Complementary Therapies in Medicine, vol. 19, no. 6, pp. 303-310, 2011.

[6] J. Frawley, J. Adams, D. Sibbritt, A. Steel, A. Broom, and C. Gallois, "Prevalence and determinants of complementary and alternative medicine use during pregnancy: results from a nationally representative sample of Australian pregnant women," Australian and New Zealand Journal of Obstetrics and Gynaecology, vol. 53, no. 4, pp. 347-352, 2013.

[7] J. Adams, D. Sibbritt, and C. W. Lui, "The use of complementary and alternative medicine during pregnancy: a longitudinal study of Australian women," Birth, vol. 38, no. 3, pp. 200-206, 2011.

[8] A. B. Mekuria, D. A. Erku, B. M. Gebresillassie, E. M. Birru, B. Tizazu, and A. Ahmedin, "Prevalence and associated factors of herbal medicine use among pregnant women on antenatal care follow-up at University of Gondar Referral and Teaching Hospital, Ethiopia: a cross-sectional study," BMC Complementary and Alternative Medicine, vol. 17, no. 1, p. 86, 2017.

[9] A. R. Pallivalappila, D. Stewart, A. Shetty, B. Pande, R. Singh, and J. S. Mclay, "Complementary and alternative medicine use during early pregnancy," European Journal of Obstetrics \& Gynecology and Reproductive Biology, vol. 181, pp. 251255, 2014.

[10] T. Hollyer, H. Boon, A. Georgousis, M. Smith, and A. Einarson, "The use of CAM by women suffering from nausea and vomiting during pregnancy," BMC Complementary and Alternative Medicine, vol. 2, p. 1, 2002.

[11] L. Gaffney and C. Smith, "Complementary and alternative medicine in obstetrics," Birth Issues, vol. 13, pp. 43-50, 2004.

[12] P. Gibson, R. Powrie, and J. Star, "Herbal and alternative medicine use during pregnancy: a cross-sectional survey," Obstetrics \& Gynecology, vol. 97, no. 4, pp. S33-S45, 2001.

[13] A. Ranzini, A. Allen, and Y. Lai, "Use of complementary medicines and therapies among obstetric patients," Obstetrics \& Gynecology, vol. 97, no. 4, article S46, 2001.

[14] J. Headley, K. Northstone, H. Simmons, and J. Golding, "Medication use during pregnancy: data from the Avon Longitudinal Study of Parents and Children," European Journal of Clinical Pharmacology, vol. 60, no. 5, pp. 355-361, 2004.

[15] H. Mohamed, J. Abdin, and K. D. Al, "Knowledge, attitude and practice of complementary and alternative medicine (CAM) among pregnant women: a preliminary survey in Qatar," Middle East Journal of Family Medicine, vol. 7, no. 10, pp. 5-14, 2010.

[16] I. O. Yasser, F. F. Nadia, and I. A. Mohamed, "Use of herbal medicines among pregnant women attending family health centers in Alexandria," Middle East Fertility Society Journal, vol. 19, pp. 42-50, 2014.

[17] D. D. Glover, M. S. Amonkar, B. F. Rybeck, and T. S. Tracy, "Prescription, over-the-counter, and herbal medicine use in a rural, obstetric population," American Journal of Obstetrics and Gynecology, vol. 188, no. 4, pp. 1039-1045, 2003.

[18] H. Nordeng and G. C. Havnen, "Use of herbal drugs in pregnancy: a survey among 400 Norwegian women," Pharmacoepidemiology and Drug Safety, vol. 13, no. 6, pp. 371-380, 2004.

[19] D. A. Forster, A. Denning, G. Wills, M. Bolger, and E. McCarthy, "Herbal medicine use during pregnancy in a group of Australian women," BMC Pregnancy and Childbirth, vol. 6, no. 1, pp. 21-30, 2006.

[20] F. Lapi, A. Vannacci, M. Moschini et al., "Use, Attitudes and Knowledge of Complementary and Alternative Drugs (CADs) 
among Pregnant Women: A Preliminary Survey in Tuscany," Evidence-based Complementary and Alternative Medicine, vol. 7, no. 4, pp. 477-486, 2010.

[21] J. M. Wilkinson, "What do we know about herbal morning sickness treatments? A literature survey," Midwifery, vol. 16, no. 3, pp. 224-228, 2000.

[22] T. Fleming, PDR for herbal medicines, no. article 121,414, 522, 649, 2009Thomson health care Inc, USA, 4th edition, 2009.

[23] Y. I. Orief, N. F. Farghaly, and M. I. A. Ibrahim, "Use of herbal medicines among pregnant women attending family health centers in Alexandria," Middle East Fertility Society Journal, vol. 19, no. 1, pp. 42-50, 2012.

[24] D. Tiran, "The use of herbs by pregnant and childbearing women: a risk-benefit assessment," Complementary Therapies in Nursing \& Midwifery, vol. 9, no. 4, pp. 176-181, 2003.

[25] D. M. Marcus and W. R. Snodgrass, "Do no harm: avoidance of herbal medicines during pregnancy," Obstetrics and Gynecology, vol. 105, 5, Part 1, pp. 1119-1122, 2005.

[26] L. Cuzzolin and G. Benoni, "Safety issues of phytomedicine in pregnancy and pediatrics," in Herbal Drugs: Ethnomedicine to Modern Medicine, K. J. Ramawat, Ed., p. 382, Springer-Verlag, Berlin Heidelberg, 2009.

[27] L. Holst, H. Nordeng, and S. Haavik, "Use of herbal drugs during early pregnancy in relation to maternal characteristics and pregnancy outcome," Pharmacoepidemiology and Drug Safety, vol. 17, no. 2, pp. 151-159, 2008.

[28] D. H. Adawi, Prevalence and predictors of herb use during pregnancy (a study at Rafidia Governmental Hospital/ Palestine), 2012, August 2018, http://scholar.najah.edu/sites/default/ files/all-thesis/deema_adawi.pdf.

[29] F. H. Dabaghian, M. A. Fard, A. Shojaei, S. Kianbakht, N. Zafarghandi, and A. Goushegir, "Use and attitude on herbal medicine in a group of pregnant woman in Tehran," Journal of Medicinal Plants, vol. 11, no. 41, pp. 22-33, 2012.

[30] E. Ernst, "Risk associated with complementary therapies," in Meyler's side effects of drugs, D. MNG and J. K. Aronson, Eds., p. 1649, Elsevier, Amsterdam, 14th edition, 2000.

[31] G. Pinn and L. Pallett, "Herbal medicine in pregnancy," Complementary Therapies in Nursing \& Midwifery, vol. 8, no. 2, pp. 77-80, 2002.

[32] Z. Shewamene, T. Dune, and C. A. Smith, "The use of traditional medicine in maternity care among African women in Africa and the diaspora: a systematic review," BMC Complementary and Alternative Medicine, vol. 17, no. 1, p. 382, 2017.

[33] L. J. John and N. Shantakumari, "Herbal medicines use during pregnancy: a review from the Middle East," Oman Medical Journal, vol. 30, no. 4, pp. 229-236, 2015.

[34] A. T. Elolemy and A. M. Albedah, "Public knowledge, attitude and practice of complementary and alternative medicine in Riyadh region, Saudi Arabia," Oman Medical Journal, vol. 27, no. 1, pp. 20-26, 2012.

[35] K. Thomas and P. Coleman, "Use of complementary or alternative medicine in a general population in Great Britain. Results from the National Omnibus survey," Journal of Public Health (Oxford, England), vol. 26, no. 2, pp. 152-157, 2004.

[36] A. Y. Duraz and S. A. Khan, "Knowledge, attitudes and awareness of community pharmacists towards the use of herbal medicines in Muscat region," Oman Medical Journal, vol. 26, no. 6, pp. 451-453, 2011.

[37] M. C. Mothupi, "Use of herbal medicine during pregnancy among women with access to public healthcare in Nairobi,
Kenya: A cross-sectional survey," BMC Complementary and Alternative Medicine, vol. 14, no. 1, p. 432, 2014.

[38] G. Bodeker and F. Kronenberg, "A public health agenda for traditional, complementary and alternative medicine," American Journal of Public Health, vol. 92, no. 10, pp. 1582-1591, 2002.

[39] V. N. Addo, "Herbal medicines: socio-demographic characteristics and pattern of use by patients in a tertiary obstetrics and gynaecology unit," Journal of Science and Technology, vol. 27, no. 3, pp. 149-160, 2007.

[40] I. Tamuno, A. Omole-Ohonsi, and J. Fadare, "Use of herbal medicine among pregnant women attending a tertiary hospital in Northern Nigeria," The Internet Journal of Gynecology and Obstetrics, vol. 15, no. 2, 2011. 